Pacific Journal of Mathematics

EXISTENCE OF LEVI FACTORS IN CERTAIN ALGEBRAIC 


\title{
EXISTENCE OF LEVI FACTORS IN CERTAIN ALGEBRAIC GROUPS
}

\author{
J. E. HumphreYS
}

If $G$ is a connected algebraic linear group with unipotent radical $U$, Borel and Tits define a Levi factor of $G$ to be any connected reductive subgroup $L$ of $G$ such that $G=L . U$ (semidirect product in the sense of algebraic groups). This differs from the usual notion of Levi decomposition in Lie theory but leads to equivalent results at characteristic 0 . The existence of Levi factors at characteristic $p$ is problematic, in view of an example of a group having no Levi factor constructed by Chevalley (unpublished). In this note sufficient conditions are given for a Levi factor to exist, based on the structure of the Lie algebra of $G$.

THEOREM. Let $G$ be a connected algebraic linear group defined over a field of characteristic $p>2$, with unipotent radical $U$. Denote by $\mathbb{B S}, \mathfrak{U}$ the respective Lie algebras, and suppose the following conditions are satisfied:

(a) $(\mathfrak{S}=\mathfrak{L}+\mathfrak{H}$, where $\mathfrak{Z}$ is a reductive subalgebra (definition below).

(b) If $T$ is a maximal torus of $G$ whose Lie algebra is included in $\mathbb{R}$, then Ad $T$ stabilizes \& (where Ad: $G \rightarrow$ Aut (S) is the adjoint representation of $G$ ).

(c) Distinct maximal tori of $G$ have distinct Lie algebras. Then $G$ has a Levi factor $L$, whose Lie algebra is $\mathfrak{R}$.

It should be observed that, in the presence of (c), conditions (a) and (b) are necessary for the existence of a Levi factor [3, § 11]. Condition (c) is far from necessary, as easy examples show, but it is satisfied in certain cases of interest. In fact (c) is equivalent to the requirement that the Lie algebra of a Cartan subgroup of $G$ be a Cartan subalgebra of (S).

We begin by summarizing some facts $[3, \S 9,11]$ about the Lie algebra $B$ of a connected algebraic linear group $G$ defined over a field of characteristic $p>2$. This restriction on $p$ will be assumed throughout the paper. Using a Jordan decomposition theorem of Borel and Springer [1, Prop. 1.3] we define \&8 (or a subalgebra of (S) to be reductive if it has no nontrivial nil ideal (= ideal consisting of nilpotent elements). A maximal torus of (S) is a subalgebra of maximal dimension consisting of commuting semisimple elements. Then:

(1) The Lie algebra $\mathfrak{U}$ of $U$ is the largest nil ideal of $\mathscr{S}$. In particular, $G$ is reductive if and only if $\$ S$ is reductive. 
(2) If $L$ is a reductive subgroup of $G$ such that $G=L . U$ is a semidirect product of abstract groups, then the product is semi-direct in the sense of algebraic groups, i.e. $\mathbb{B S}=\mathfrak{Q}+\mathfrak{U}$ is a semi-direct sum, where $\mathbb{R}$ is the Lie algebra of $L$.

(3) If $G$ is reductive, maximal tori of $G$ and $\$ 5$ correspond one-toone. In any case, a maximal torus of $\mathbb{B}$ is the Lie algebra of at least one maximal torus of $G$.

(4) If $G$ is reductive, maximal tori of \&s are Cartan subalgebras.

Lemma. Let $G$ be a connected reductive algebraic group, with Lie algebra (S. Then $G$ (resp. (S) is generated by its maximal tori.

Proof. The assertion for $G$ follows from the fact that the semisimple elements of $G$ form a dense subset (see [5, 2.14]: this extends at once from semisimple to reductive groups). The assertion for (B) is immediate if $B S$ is a three-dimensional simple algebra and follows in the general case because $\mathbb{B}$ is generated by any maximal torus along with certain three-dimensional simple subalgebras [3, 3.9 and 11.9].

Proof of theorem. We proceed by induction on $\operatorname{dim} G$, the onedimensional case being trivial. In view of (1) and (2) above, it will suffice to find a connected reductive subgroup $L$ of $G$ whose Lie algebra is $\mathbb{L}$ (for $L$ is then automatically a Levi factor). For purposes of induction, observe that: $\left({ }^{*}\right)$ if $H$ is a closed connected subgroup of $G$ whose Lie algebra includes 2 , then $H$ satisfies conditions (a)-(c). For let $f: G \rightarrow \bar{G}=G / U$ be the canonical map; the differential $d f$ maps $\mathbb{Z}$ isomorphically onto the Lie algebra $\overline{\mathscr{S}}$ of $\bar{G}$. Since in any case $d f(\mathbb{R})$ is included in the Lie algebra of $f(H)$, it follows that $f(H)=\bar{G}$. Now $H \cap U$ lies in the unipotent radical of $H$, so by comparison of dimensions we have the decomposition of the Lie algebra $\mathfrak{S}$ of $H$ required for (a): $\mathfrak{S}=\mathfrak{L}+\mathfrak{U}^{\prime}, \mathfrak{u}^{\prime}$ the Lie algebra of $H \cap U$. Since $H$ has maximal rank in $G,(b)$ and (c) are obviously satisfied and $\left(^{*}\right)$ is valid.

Next, let $H$ be the subgroup of $G$ generated by all maximal tori whose Lie algebras lie in \&. Then $H$ is a closed connected subgroup (all tori are connected). The Lemma along with (3) above implies that $\mathfrak{Q}$ lies in the Lie algebra of $H$, so $\left(^{*}\right)$ applies and we can appeal to the induction hypothesis if $H \neq G$.

This leaves the case $H=G$. We will produce the desired Levi factor, which in view of (c) will contain all maximal tori whose Lie algebras lie in $\mathbb{Q}$ (so in this case $G$ itself will turn out to be reductive). By (b) we have that Ad $T$ stabilizes $\&$ for each maximal torus $T$ with Lie algebra contained in $\mathfrak{R}$; since these tori generate $G$, Ad $G$ stabilizes $\mathfrak{l}$. As is well known, this implies $[\mathbb{S}, \mathfrak{l}] \subseteq \mathfrak{l}$. In particular, $[\mathfrak{U}, \mathfrak{l}]=$ 
0 since $\mathfrak{U}$ is also an ideal. Let $x$ be any semisimple element of $\mathfrak{L}, \mathfrak{T}$ some maximal torus of $\mathbb{Z}$ (hence of $(\mathfrak{S )}$ ) containing $x$. By (3) above, $\mathfrak{T}$ is the Lie algebra of a maximal torus $T$ of $G$. Applying a result of Borel and Springer [1, Prop. 1.5] to the group T.U and its Lie algebra $\mathfrak{I}+\mathfrak{U}$, we see that the group in question centralizes $x$ because the algebra does. In view of the lemma, $U$ centralizes all of $\mathbb{R}$.

Let $u \in U$, and let $T$ be any maximal torus of $G$ with Lie algebra $\mathfrak{I}$ included in $\mathbb{R}$. Then it is easy to see that $u^{-1} T u$ has Lie algebra $u^{-1} \mathfrak{T} u=\mathfrak{T}$. By assumption (c), $u^{-1} T u=T$. But $T$ normalizes $U$, so it follows that $T$ and $U$ commute elementwise. In particular, $U$ centralizes a set of generators of $G$ and thus $U$ is central in $G$.

In order to apply a theorem of Steinberg on central extensions of finite type, a further reduction is needed. Let $f: G \rightarrow \bar{G}=G / U$ be the canonical map. $\bar{G}$ is reductive and can be written as the product of its derived group $\bar{G}^{\prime}$ and a central torus $Z$. Let $S=f^{-1}(Z)$, so $S$ is the ordinary (solvable) radical of $G$. Since $U$ is central, $S$ is clearly nilpotent and contains a unique maximal torus $S_{1}$. If $s \in S_{1}$ and $x \in G$, we have $f\left(s^{-1} x s\right)=f(x)$, so $s^{-1} x s x^{-1} \in \operatorname{Ker}(f)=U$. But then $x s x^{-1}=$ $s u$, with the left side semisimple and the right side a product of commuting semisimple and unipotent elements. Thus $u=1$, and $S$ is central in $G$ because $S=S_{1} . U$. If $S_{1}$ is nontrivial, observe that $H_{0}=f^{-1}\left(\bar{G}^{\prime}\right)$ and its Lie algebra satisfy conditions (a)-(c). The verification is straightforward for (a) and (b), using the Cartan decomposition of $\&$ along with facts summarized above. For (c) observe that the centrality of $U$ implies that maximal tori of $H_{0}$ correspond one-toone with maximal tori of $\bar{G}^{\prime}$ under $f$. But now $\operatorname{dim} H_{0}<\operatorname{dim} G$, so the induction hypothesis yields a semisimple subgroup $R$ of $H_{0}$ with Lie algebra included in 2 , such that the product $L=R . S_{1}$ is the desired Levi factor of $G$.

We can therefore assume without loss of generality that $\bar{G}$ is semisimple. Thus $\bar{G}$ is a product of certain normal subgroups of simple type. By imitating the procedure of the preceding paragraph (with recourse to the Lemma) one reduces readily to the case where $\bar{G}$ itself is of simple type. (Alternatively one can extend Steinberg's results discussed below from the simple to the semisimple case.) Since $\bar{G}$ is now its own derived group, and maximal tori of $G$ correspond to maximal tori of $\bar{G}$ under $f$, it follows (since $U$ is central) that all maximal tori of $G$ lie in the derived group $G^{\prime}$. But these tori generate $G$, so $G=G^{\prime}$.

In [4] Steinberg constructs a simply connected covering group $\Gamma$ for each simple type (by a uniform procedure involving generators and relations). In particular, there is a canonical epimorphism $\pi: \Gamma \rightarrow \bar{G}$. We will apply Theorem 5.2 of [4] to the situation 


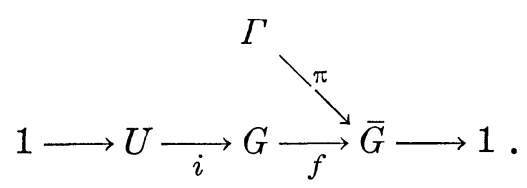

It must be observed that the indicated extension of $\bar{G}$ is central and of finite type, i.e. $u^{n}=1$ for some fixed $n$ and all $u \in U$. This is easy to check, using a composition series for $U$ with factors isomorphic to the additive group of the universal domain. Therefore a homomorphism (of abstract groups) $\pi_{0}: \Gamma \rightarrow G$ exists, with $\pi=f \pi_{0}$. Let $L=\pi_{0}(\Gamma)$. Since $\Gamma$ has finite center $[4,3.2]$ and $f$ is surjective, the relation $\pi=f \pi_{0}$ implies $G$ is generated by $L$ and $U$, while $L \cap U$ is finite. But $U$ is central, so $G=G^{\prime}=L^{\prime}$ and $U \subseteq L$. Thus $U$ is finite (and connected), hence trivial. We conclude in this case that $G$ is already reductive, which completes the proof.

REMARKs. (1) In case $G$ is a subgroup of maximal rank in some reductive group $H$, condition (c) holds for $G$ because of statement (3) above. Thus our theorem may be viewed as a partial generalization of $[2,3.14]$.

(2) The theorem reduces in some measure the problem of Levi decompositions in algebraic groups to the corresponding problem in algebraic Lie algebras. The latter problem may be simpler to handle, but little seems to be known. The "classical" notion of Levi decomposition (semisimple plus solvable) fails for rather unimportant reasons in such cases as the Lie algebra of $S L(p, K)$, and it may be hoped that the notion developed by Borel and Tits will prove to be more manageable when applied to Lie algebras. (Cf. the paper by H. E. Campbell, Pacific J. Math. 7(1957), 1325-1331.)

(3) An example is constructed in [2, 3.15] to show that Levi factors need not be conjugate. It can be verified that this example satisfies our conditions (a)-(c), which suggests that conjugacy may be a rather delicate question in prime characteristic.

\section{REFERENCES}

1. A. Borel and T. A. Springer, Rationality properties of linear algebraic groups, Proc. Symposia in Pure Math., Vol. IX, Amer. Math. Soc., Providence, 1966.

2. A. Borel and J. Tits, Groupes réductifs, Publ. Math. I.H.E.S. 27 (1965), 55-150. 3. J. E. Humphreys, Algebraic groups and modular Lie algebras, Amer. Math. Soc. Memoir, Providence, 1967.

4. R. Steinberg, Générateurs, rélations et revêtements de groupes algébriques, Colloque sur la théorie des groupes algébriques, Brussels, 1962.

5. - Regular elements of semisimple algebraic groups, Publ. Math. I.H.E.S. 25 (1965), 49-80.

Received January 10, 1967.

UNIVERSITY OF OREGON 


\section{PACIFIC JOURNAL OF MATHEMATICS}

\section{H. ROYDEN}

Stanford University

Stanford, California

\author{
J. P. JANS \\ University of Washington \\ Seattle, Washington 98105
}

\section{EDITORS}

\author{
J. DugundJI \\ Department of Mathematics \\ Rice University \\ Houston, Texas 77001 \\ Richard ARENS \\ University of California \\ Los Angeles, California 90024
}

\section{ASSOCIATE EDITORS}
E. F. BECKENBACH
B. H. NeumanN
F. WOLF
K. YOSIDA

\section{SUPPORTING INSTITUTIONS}

\author{
UNIVERSITY OF BRITISH COLUMBIA \\ CALIFORNIA INSTITUTE OF TECHNOLOGY \\ UNIVERSITY OF CALIFORNIA \\ MONTANA STATE UNIVERSITY \\ UNIVERSITY OF NEVADA \\ NEW MEXICO STATE UNIVERSITY \\ OREGON STATE UNIVERSITY \\ UNIVERSITY OF OREGON \\ OSAKA UNIVERSITY \\ UNIVERSITY OF SOUTHERN CALIFORNIA
}

\author{
STANFORD UNIVERSITY \\ UNIVERSITY OF TOKYO \\ UNIVERSITY OF UTAH \\ WASHINGTON STATE UNIVERSITY \\ UNIVERSITY OF WASHINGTON \\ AMERICAN MATHEMATICAL SOCIETY \\ CHEVRON RESEARCH CORPORATION \\ TRW SYSTEMS \\ NAVAL ORDNANCE TEST STATION
}

Mathematical papers intended for publication in the Pacific Journal of Mathematics should be typewritten (double spaced). The first paragraph or two must be capable of being used separately as a synopsis of the entire paper. It should not contain references to the bibliography. Manuscripts may be sent to any one of the four editors. All other communications to the editors should be addressed to the managing editor, Richard Arens at the University of California, Los Angeles, California 90024.

50 reprints per author of each article are furnished free of charge; additional copies may be obtained at cost in multiples of 50 .

The Pacific Journal of Mathematics is published monthly. Effective with Volume 16 the price per volume (3 numbers) is $\$ 8.00$; single issues, $\$ 3.00$. Special price for current issues to individual faculty members of supporting institutions and to individual members of the American Mathematical Society: $\$ 4.00$ per volume; single issues $\$ 1.50$. Back numbers are available.

Subscriptions, orders for back numbers, and changes of address should be sent to Pacific Journal of Mathematics, 103 Highland Boulevard, Berkeley 8, California.

Printed at Kokusai Bunken Insatsusha (International Academic Printing Co., Ltd.), 7-17, Fujimi 2-chome, Chiyoda-ku, Tokyo, Japan.

PUBLISHED BY PACIFIC JOURNAL OF MATHEMATICS, A NON-PROFIT CORPORATION

The Supporting Institutions listed above contribute to the cost of publication of this Journal, but they are not owners or publishers and have no responsibility for its content or policies. 


\section{Pacific Journal of Mathematics}

A. A. Aucoin, Diophantine systems ............................. 419

Charles Ballantine, Products of positive definite matrices. I ............... 427

David Wilmot Barnette, A necessary condition for d-polyhedrality ............ 435

James Clark Beidleman and Tae Kun Seo, Generalized Frattini subgroups of finite groups ......................................... 441

Carlos Jorge Do Rego Borges, A study of multivalued functions ............. 451

William Edwin Clark, Algebras of global dimension one with a finite ideal

lattice ...............................................

Richard Brian Darst, On a theorem of Nikodym with applications to weak convergence and von Neumann algebras .........................

George Wesley Day, Superatomic Boolean algebras .....................

Lawrence Fearnley, Characterization of the continuous images of all

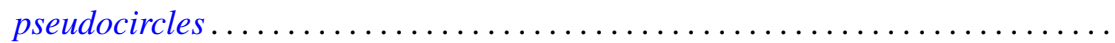

Neil Robert Gray, Unstable points in the hyperspace of connected subsets....... 515

Franklin Haimo, Polynomials in central endomorphisms .................. 521

John Sollion Hsia, Integral equivalence of vectors over local modular lattices . . . . 527

Jim Humphreys, Existence of Levi factors in certain algebraic groups .......... 543

E. Christopher Lance, Automorphisms of postliminal $C^{*}$-algebras ............ 547

Sibe Mardesic, Images of ordered compacta are locally peripherally metric . . . . 557

Albert W. Marshall, David William Walkup and Roger Jean-Baptiste Robert Wets,

Order-preserving functions: Applications to majorization and order

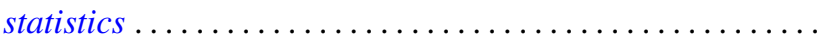

Wellington Ham Ow, An extremal length criterion for the parabolicity of

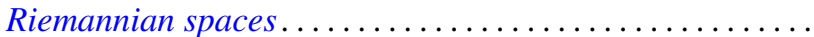

585

Wellington Ham Ow, Criteria for zero capacity of ideal boundary components of

Riemannian spaces...................................... 591

J. H. Reed, Inverse limits of indecomposable continua .................. 597

Joseph Gail Stampfli, Minimal range theorems for operators with thin spectra . . . 601

Roy Westwick, Transformations on tensor spaces..................... 613

Howard Henry Wicke, The regular open continuous images of complete metric

spaces ........................................... 621

Abraham Zaks, A note on semi-primary hereditary rings .............. 627

Thomas William Hungerford, Correction to: "A description of $\operatorname{Mult}_{i}\left(A^{1}, \cdots, A^{n}\right)$

by generators and relations" ............................. 629

Uppuluri V. Ramamohana Rao, Correction to: "On a stronger version of Wallis' formula".............................................. 629

Takesi Isiwata, Correction: "Mappings and spaces" ................... 630

Henry B. Mann, Josephine Mitchell and Lowell Schoenfeld, Correction to:

"Properties of differential forms in $n$ real variables" .... . .

James Calvert, Correction to: "An integral inequality with applications to the

Dirichlet problem"............................. 